\title{
Desenvolvimento de uma Ferramenta Computacional baseada em Lógica Fuzzy para Armazenamento e Análise de Dados Físico- Químicos e Biológicos do Rio Cachoeira-BA
}

\author{
João Gabriel Ganem Barbosa*, Francisco Bruno Oliveira Souza \\ Universidade Estadual de Santa Cruz - Departamento de Ciências Exatas e Tecnológicas \\ 45662-900 - Rodovia Ilhéus/Itabuna, Km 16, BA, Brasil \\ E-mail: fbsoliveira@uesc.br,j.gabrielgb@gmail.com \\ Elaine Teixeira Oliveira*, Fábio Flores Lopes \\ Universidade Estadual de Santa Cruz - Departamento de Ciências Biológicas \\ 45662-900 - Rodovia Ilhéus/Itabuna, Km 16, BA, Brasil \\ E-mail: fabiologo5@hotmail.com, lany_tex@hotmail.com
}

\section{RESUMO}

A lógica fuzzy é uma técnica de inteligência artificial baseada no conhecimento heurístico, geralmente representado por um conjunto de expressões condicionantes para representar os fenômenos e os processos, com base no conhecimento de especialista dos mesmos. [2] De forma mais objetiva, define-se ainda lógica fuzzy como sendo uma ferramenta capaz de capturar informações vagas, em geral descritas em uma linguagem natural e convertêlas para um formato numérico, de fácil manipulação pelos computadores de hoje em dia. [3]

O Rio Cachoeira, com cerca de $300 \mathrm{~km}$ de extensão, exerce uma grande influência na região Sul da Bahia nas áreas de agricultura e pecuária, além de servir como fonte de alimento através da pesca para diversas famílias e comunidades que moram próximas às margens do rio.[1]

Duas principais cidades da região que são banhadas pelo Rio Cachoeira, Itabuna e Ilhéus, despejam todo esgoto nas águas do rio que, em conjunto com lixo industrial e urbano, contribuem para a poluição das águas de um dos maiores rios da Bahia.

Tendo em vista essa problemática, foi desenvolvida uma ferramenta computacional para armazenamento e análise de dados físico-químicos e biológicos para poder medir e caracterizar a qualidade da água no Rio Cachoeira. Pesquisadores e biólogos têm coletado periodicamente desde 2010 amostras em seis pontos do Rio Cachoeira, desde o Estivo, dez quilômetros acima de Itapé, passando pelo Jardim das Acácias, em Itabuna e finalizando no Caminho das Sesmarias, no distrito de Banco da Vitória, município de Ilhéus, como é possível observar na figura 1. Após armazenamento destes dados, aplicam-se funções de pertinência que possibilitam expressar a qualidade da água em cada um desses pontos através de parâmetros fuzzy. Além disso, é possível fazer simulações futuras utilizando dados experimentais e também consultar amostras e análises anteriores.

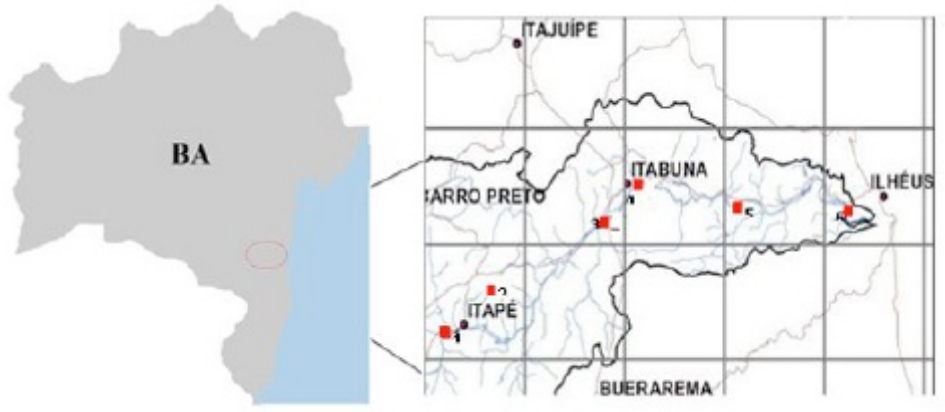

Figura 1: Mapa regional com os pontos para coleta da água destacados em vermelho 
A ferramenta é baseada em sistema web, permitindo maior flexibilidade quanto à plataforma utilizada, utilizando PHP, MySQL, HTML e CSS como linguagens e tecnologias para confecção do sistema, banco de dados e interface respectivamente. Para construir as funções de pertinência fuzzy, foram escolhidas por especialistas três substâncias principais como variáveis linguísticas, pois essas tem maior peso na qualidade do rio. São elas: Nitrato Total (NO3), Nitrogênio Amonical (NH4) e Sulfato (SO4)[4]. Os termos para cada variável linguística são Bom, Regular e Ruim, aplicados a depender do nível de entrada de cada substância.

A partir do paralelo entre as três, é possível definir se a água está com qualidade boa, regular ou ruim de acordo com uma base de regras derivada das funções de inferência. A figura 2 mostra a funções utilizadas, trapezoidal e triangular, respectivamente, para cálculo do grau de pertinência da qualidade da água. Após definidas as variáveis e funções de cada uma delas, criam-se tabelas com bases de regra do sistema e, por fim, é definido o índice final da qualidade da água através do método de Mandami seguindo a equação da figura 3, onde A, B e C são as variáveis linguísticas.

$$
\begin{gathered}
\mu \operatorname{trap}(x ; a, b, c, d)=\max \left(\min \left(x-\frac{a}{b}-a, 1, d-\frac{x}{d}-c\right), 0\right) \\
\mu \operatorname{tri}(x ; a, b, c)=\max (\min (x-a / b-a, c-x / c-b), 0)
\end{gathered}
$$

Figura 2: Função de pertinência para a quantidade de SO4 na água

$$
\mu(\mathrm{x}, \mathrm{y}, \mathrm{z})=\Phi \mathrm{c}[\mu \mathrm{A}(\mathrm{x}), \mu \mathrm{B}(\mathrm{y}), \mu \mathrm{C}(\mathrm{z})]=\min (\mu \mathrm{A}(\mathrm{x}), \mu \mathrm{B}(\mathrm{y}), \mu \mathrm{C}(\mathrm{z}))
$$

Figura 3: Fóruma para operação de Madami, que resulta em um valor de pertinência da índice de qualidade da água

Em uma determinada coleta realizada no ponto 2, localidade do Estivo, foram encontrados para as substâncias NO3, NH4 e SO4, respectivamente, concentrações de $22 \mathrm{mg} / \mathrm{L}$, $0,8 \mathrm{mg} / \mathrm{L}$ e $155 \mathrm{mg} / \mathrm{L}$. Após fuzzyficação, foi possível notar que NO3 estava em nível BOM, NH4 REGULAR e SO4 estava parcialmente em dois conjuntos, sendo 0,5 BOM e 0,25 REGULAR de um total de 1. Após aplicar regras de inferência, foi possível estabelecer um índice de 78.90 a esta amostra, em uma escala de 0 a 100, onde 0 é uma péssima condiçãoo do rio e 100 a melhor condição possível.

O projeto encontra-se em andamento e atualmente está sendo estudada a implementação de mais variáveis e graus de pertinência, deixando o sistema mais complexo e preciso, uma vez que o aumento no número de parâmetros faz o sistema ter mais nuances, com mais fidelidade às condições reais.

Palavras-chave: Lógica Fuzzy, Qualidade da Água, Rio Cachoeira

\section{Referências}

[1] Bahia, Plano Diretor de Recursos Hídricos das Bacias do Leste, Superintendência de Recursos Hídricos, UESC, Governo do Estado da Bahia, 1996.

[2] V. M. S. Barbalho, Sistemas baseados em conhecimento e lógica difusa para simulacão do processo chuva vazão. Tese de Doutorado COPPE UFRJ, 2001.

[3] H. A. Oliveira Júnior, Lógica Difusa aspectos práticos e aplicações. Rio de Janeiro Interciência, 1999.

[4] C. F. A. Pires, E. T. Oliveira; F. B. S. Oliveira; F. F. Lopes, Desenvolvimento de uma Ferramenta para Análise da Qualidade da Água do Rio Cachoeira Utilizando Lógica Fuzzy, Anais do XVI Encontro de Modelagem Computacional/IV Encontro de Ciência e Tecnologia de Materiais/III Encontro Regional de Matemática Aplicada e Computacional, UESC, 2013. 